\title{
Feminism and Ethnicity and Selected Women Artists of Color

\author{
Jessie Whitehead
}

\begin{abstract}
The body of literature on the intersections of culture, gender, and race has not been seriously incorporated into the general accounts of women artists. Published literature reveals that race is equal to or perhaps more important than gender to women of color. This paper describes my proposed study investigating what influence feminism and ethnicity may have in the lives of Black American and Native American women artists. Recent research is limited regarding these issues in association with women artists of color. This study can add to the growth of this research.

This study is based on an inquiry regarding the influence of feminism and ethnicity in the lives of women artists of color. Women artists of color view themselves in relationship to factors which can include race, gender, sex, and class (Machida, 1991). Two of these factors are related to the areas of focus of this study. Gender is considered a component of feminism and race a component of ethnicity. An analysis of gender and race is based on the assumption that individuals and groups possess coherent and stable identities and interests grounded in unmediated experiences. Feminist theory, characterized by such universalism, has relied upon this concept of collective and individual identity (Dugger, 1995).

The issues of racism and feminism are linked in the sense that the struggles are connected, and discrimination against any group diminishes all. The struggles of women artists of color are qualitatively different because the oppression of sexism is amplified by that of racism, classism, and religious and ethnic discrimination (Touchette, 1991).

Feminist philosophy is based on the supposition that women are as important as men, and it has added a new dimension to philosophy in its insistence that a person's gender conditions the way he or she approaches the world (Solomon \& Higgins, 1996). The feminist movement of the 1960's sought to develop a sense of sisterhood. Some individuals, however, questioned the movement's emphasis on sisterhood. The questioning was based on a concern that such a focus marginalizes those women different from the white middle-class women who were leading the movement. Women of nonwhite ethnicity were included in those individuals marginalized. More recent philosophical feminism has attempted to correct the earlier marginalization in its redefinition from the points of view of women from minority groups (Solomon \& Higgins, 1996).
\end{abstract}




\section{Overview of Study}

The main question investigated in this study is, how, if at all, have feminism and ethnicity influenced selected Black American and Native American women artists? The areas of feminism and ethnicity are comprehensive, thus, an attempt to answer such an extensive question would be a difficult endeavor. As a result, subtopics generated by the review of literature have been developed to narrow the focus of the study. The subtopics or questions include:

1. What is the artist's definition of the term feminism?

2. What is the artist's definition of the term ethnicity?

3. How has feminism affected the artist in hor

(a) education, (b) professional life, (c) identity, and (d) art production?

4. What role has ethnicity played in the artist's

(a) education, (b) professional life, (c) identity, and (d) art production?

An exploratory study is being conducted, addressing the artists' life experiences regarding feminism and ethnicity. This research approach is of a qualitative and inductive nature.

Gay (1996) informs us that qualitative research is the collection and analyses of narrative data in an attempt to gain insight. The approach to this inquiry is inductive in that the research is seeking to derive and describe feelings that will promote a greater understanding of how, if at all, feminism and ethnicity have influenced Native American and Black American women artists. Research will be conducted through the use of a limited sample of Native American and Black American women artists employing case studies. Any conclusions will be based on the artists' individual experiences without attempting generalizations to other Native American and Black American women artists.

\section{Importance of the Study}

Investigating this question explores the "problem" of feminism and ethnicity in connection with selected women artists of color. Women artists in general are under-represented in the study of art, and women artists of color are represented to a lesser degree. The review of literature reveals limited studies on the intersection of feminism and ethnicity concerning the lives of Black American and Native American women artists. Research into the influences of feminism and ethnicity regarding Black American and Native American women artists will contribute to the growth of this underdeveloped area.

What implication does this have in the area of art education? By the turn of the century, LaDuke (1992) states that one out of four Americans attending school will be of Native American, African, Latin, or Asian heritage. LaDuke (1992) also asks how is the reality of this situation reflected in education and the art establishment. This reality and query are motivating factors and a guiding force in insuring that information concerning the lives of persons of color is more fully incorporated into art educational settings. A potential use of this research is to 
contribute to the information base of teaching and learning in art education. Art education is not restricted to teaching and learning in the classroom but is also about educating the public as a whole. Data gathered as a result of this study can be incorporated into additional avenues of instruction such as educational departments of museums and cultural centers.

\section{Definition of Terms}

For the purpose of this study, the term ethnicity is initially defined as derivative of the adjective ethnic: of or relating to races or large groups of people classed according to common traits and customs (The Merriam -Webster Dictionary, 1998). Feminism is defined as a doctrine that advocates or demand for women the same rights granted men, as in political or economic status (The American Heritage Dictionary of the English Language, 1971). The review of literature, however, reveals various definitions of both terms. Due to the various meanings of ethnicity and feminism, it is of significance to investigate these areas prior to an attempt to establish their significance in the lives of the artists.

\section{Feminism}

What is meant by the word, feminism? It can be daunting, complicated and difficult to define. Others (Britto, 1994; Brookner, 1991; Moore, 1998) have acknowledged this. Britto (1994) aptly describes feminism as a polysemic word with the scope and boundaries depending on who defines it and why it is initially defined. Britto (1994) states that women are splintered by numerous divisions, contradictory interests and oppressive processes resulting in no one definition fitting all interests. Brookner (1991) views feminism as a commitment to full humanity of all women and men, and a dismantling of patriarchal values that inhibit.

A contemporary definition of feminism is the theory of the political, economic, and social equality of the sexes (Merriam-Webster Dictionary, 1998). The Living Webster Encyclopedia Dictionary of English Language (1972) defines feminism as a doctrine advocating that social and political rights of women be equal to those possessed by men. Individuals have also defined feminism. Barbara Smith (as cited by Ryan, 1992) defines feminism as the political theory and practices to free all women: women of color, working-class women, poor women, physically challenged women, lesbians, old women, as well as white economically privileged heterosexual women. Ryan (1992) also cites Charlotte Bunch's definition of feminism, described as a movement for the liberation of women, because women's oppression is deeply embedded in everything, and must necessarily then, be a movement for the transformation of the whole society.

Feminism encompasses numerous varied movements. Amazon, cultural, eco, liberal, socialist, radical, and separatists are a few of the varied forms of feminism that have been identified and defined (Moore, 1998). Amazon feminism rejects the idea that certain characteristics or interests are inherently masculine (or 
feminine), and upholds and explores a vision of heroic womanhood. Ecofeminism's basic belief is that a patriarchal society will exploit its resources without regard to long-term consequences as a result of the attitudes fostered in a patriarchal/hierarchical society. Liberal feminism is a form of feminism that works within the structure of mainstream society to integrate women into that structure. Hein (1990) informs us that "isms" can be misleading with a tendency to think of them as promotional, advancing the cause or at least foregrounding the subject to which the suffix is attached. The terminal identification of "ism" bestows significance upon a category that may have existed as a concept prior to the appendage of its "ism." Feminism is an example of a word that expresses semantic innovation creating new ways of thinking, new meanings, and new categories of critical reflection. Hein (1990) further elaborates that it is a term that does not pertain to women as objects of love or hatred, or of social (in)justice, but fixes upon the perspective that women bring to experience as subjects. The word feminism has associations favorable to women mainly because it accords subject status.

According to Lippard (1990), women and artists of color have struggled to be perceived as subject rather than object. False identities have led women and people of color to an obsession with self-definition and to a re-creation of identity from the inside out. The feminist movement's rehabilitation of subjectivity has been a model for an on-going search for identity within minority groups (Lippard, 1990).

Feminism remains an ever-present issue in the worlds of politics, work, and everyday life (Lovelace, 1997). The relationship between feminism and diverse cultures became an area of concern among American women artists as the decade of the 1970's drew to a close (Brodsky, 1994). Within the feminist movement, women of color led the way in creating effective forms of social protest art. Yet, women artists of color were not an integral part in the planning of alternative exhibits, nor were they deeply involved in women's galleries (Brodsky, 1994). Even with the efforts and good intentions of white women in the area of political art, racial separation and racism existed from the beginning within the feminist art movement (Lopez \& Roth, 1994). Black women artists, along with other women of color monitoring the feminist movement, resisted white women artists' assumptions that black art had no choice but to be political. As a result, many women of color kept a distance from the feminist mainstream early in its history (Lippard, 1990). The feminist art movement suggests identity is prioritized by gender, not race. For women artists of color, however, ethnicity more than gender appeared to shape their primary identities, loyalties, and the content of their art.

\section{Ethnicity}

The definitions of ethnicity, as of feminism, are varied. This is evidenced by the numerous definitions of ethnicity and its related terms of ethnic group and ethnic identity contained in the review of literature. The concept ethnicity is a derivative of the adjective 'ethnic' in the English language and goes back to the 
Middle Ages. The English adjective 'ethnic' derives from ancient Greek 'ethnos' used as a synonym of gentile, that is, non-Christian and non-Jewish pagan in New Testament Greek. In French, the term survives as 'ethnie', with the associated adjective 'ethnique' (Hutchinson \& Smith, 1996).

The term "ethnicity" is a recent one, even though the sense of kinship, group solidarity, and common culture to which it refers are old (Hutchinson \& Smith, 1996). The term first appeared in the 1950's in the English language, initially recorded in the Oxford English Dictionary of 1953 . It can mean the essence of an ethnic group, or quality of belonging to an ethnic community or group, or what it is you have if you are an ethnic group (Chapman, et al, as cited by Hutchinson \& Smith, 1996), in the context of other ethnic groups. It may also refer to a field of study dealing with the classification of peoples, and the relations between groups in context of "self-other" distinctions (Eriksen, as cited by Hutchinson \& Smith, 1996). Additional definitions or explanations of the term ethnicity include ethnic-based action (Royce, 1982) and group-shared patterns of rules of social interaction, values, social customs, behavioral roles, perceptions, and language usage (Barth; Ogbu, as cited by Canino, 1995).

Contemporary definitions of ethnicity are composed of objective and subjective criteria (Royce, 1982). A review of over 25 definitions of ethnicity by Isajiw (as cited by Royce, 1982) reveals attributes checked for presence or absence and attributes based on feelings or status. Twelve characteristics are identified, with common ancestral origin, same culture or customs, religion, race or physical characteristics, and language appearing the most often. Remaining characteristics include a sense of peoplehood and common values. Royce also informs the reader that in 1973, the Social Science Research Council established six criteria or features of a working definition of ethnicity: (a) past-oriented group identification emphasizing origins; (b) some conception of cultural and social distinctiveness; (c) relationship of ethnic group to a component unit in the broader system of social relations; (d) the fact that ethnic groups are larger than kin or locality groups and transcend face-to-face interaction; (e) different meanings for ethnic categories both in different social settings and for different individuals; and (f) the assumption that ethnic categories are emblematic, having names with meaning both for members and for analysis (p. 24).

Concepts such as ethnic identity, ethnic origin, and ethnocentrism have emerged in the study of ethnicity, conceived as a field of social phenomena. Ethnic identity and ethnic origin refer to the individual level of identification with a culture defined collectively, with a sense on the part of the individual that she or he belongs to a particular cultural community.

All people derive from an original heritage, and all people are ethnic (Grisby, 1977). Ethnic is often viewed as a manner of only identifying members of minority United States populations, such as American Indians, African-Americans, Mexican-Americans, and Asian-Americans (Grisby, 1977). Ethnic and racial groups are not completely independent and self-contained. They are part of a larger societal system that influences, shapes, and defines their character and 
determines life circumstances. This results in internal and external sets of opposition. The internal set serves to establish and maintain a group's distinctive we-ness, and the external set serves to shape and to designate its they-ness (Ringer \& Lawless, 1989).

The culture of shared values, beliefs, institutions, styles of life, and general designs for living differ among ethnic groups. Each has at its center of values and beliefs a group of "truths" which justify the group's existence. Sacred values and symbols are located at the center of what sustains feelings of pride and ethnocentrism. Differences exist between ethnic groups and the larger society over the definition of their distinctiveness. Of equal significance are differences that characterize the evaluation of distinctiveness. An ethnic group positively values its distinctiveness, whereas the larger society may evaluate it negatively (Ringer \& Lawless, 1989). Definitions and meanings of race and ethnicity are to some degree determined by historical forces that shape society (Harris, 1995).

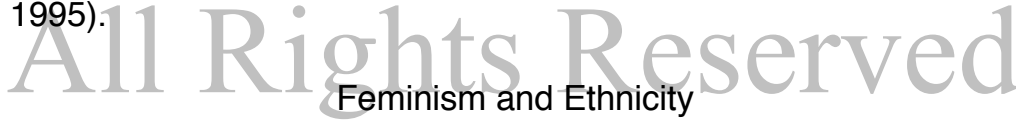

According to Grisby (1977), a broader definition of ethnicity incorporates race, culture, and language. Stein (1994) states that for "hyphenated" feminists, such as African-Americans, Asian-Americans, and Mexican-Americans, issues of gender go hand in hand with questions of race and cultural identity. A study by Machida (1991) provided an arena which investigated the relationship that gender, race, and ethnicity occupy in Asian-American women's definition of self.

A summary of the major issues of this study reveals that gender is not necessarily the most important issue for many Asian-American women artists. It is viewed as part of the network of social and political concerns. The relationship to feminism is a conflicted one, as with other women of color. Touchette (1991) feels that struggles of women artists of color are qualitatively different because the oppression of sexism is amplified by that of racism, classism, religious and ethnic discrimination. Ethnic artists would still face inequity in access, visibility, and employment in the arts even if sexism were overcome. The issues of racism and feminism are linked in the sense that the struggles are connected, and discrimination against any group diminishes all (Touchette, 1991).

Touchette concludes that it is time for the majority (persons of color) to stop allowing themselves to be defined and limited; that to do so is crucial to the right to define, support, and defend artists of all ethnicities and races who create art out of their own experiences. The connections fashioned through common struggles against racism, ethnic stereotyping, colonialism and other forms of domination should be recognized, as well as an examination of what sustains parallel tradition and values (Machida, 1991). Dugger (1995), however, reminds us that, as with the history of the women's movement and Black resistance struggles, grounding politics in a common experience does not necessarily guarantee internal stability of political constituencies or facilitate coalitions. It is 
also stated by Dugger (1995) that women experience their gender, as do people of color their race in a variety of ways.

\section{Summary}

The information gained from this search thus far reveals that defining feminism and ethnicity includes a variety of meanings and interpretations. There seems to be a community of agreement, however, that feminism is woman oriented, and that ethnicity is an internally and externally constructed identity. Feminism has impacted or influenced women directly or indirectly regardless of whether one identifies herself as a feminist or not. The issue of race can be equal to or perhaps more important than gender to women of color, including women artists. The journey taken through this search also produced the discovery that recent research is limited regarding these issues in association with women artists of color. Lopez \& Roth (1994) point out a related gap in this knowledge base, in their assessment that there is an inequality of information on women of color as opposed to Euro-America women.

\section{Conclusion}

This proposed study is not seeking to answer the large question of how feminism and ethnicity have influenced the general population of Black American and Native American women artists. It is examining what influence these areas may have in the lives of selected Black American and Native American women artists. The body of literature on the intersections of culture, gender, and race has not been seriously incorporated into the general accounts of women artists

(Lopez \& Roth, 1994). This study may add to the growth of this body of literature.

\section{References}

American heritage dictionary of the English language (8th Ed.). New York: American Heritage, 1971.

Britto, V. (1994). Fields, feminism, and theories [On-line]. Available: http://www.personal.umich.edu/ fiatlux/essays/fem.paper.html

Brodsky, J. K. Exhibitions, galleries, and alternative spaces. In N. Broude \& M. D. Garrard (eds.), The Power of Feminist Art. New York: Harry N. Abrams, 1994.

Brookner, J. Feminism and students of the eighties and nineties. Art Journal (50) 11:Summer 1991.

Canino, I. A. Coping with stress through art: A program for urban minority children. In H.W. Harris, H. C. Blue, \& E. E. H. Griffith (eds.), Racial and Ethnic Identity; Psychological Development and Creative Expression. New York: Routledge, 1995. 
Dugger, K. Changing the subject: Race and gender in feminist discourse. In B. P. Bowser (ed.), Racism and Anti-Racism in World Perspective. Thousand Oaks: Sage Publications, 1995.

Gay, L. R. Educational Research - Competencies for Analysis and Application. Upper Saddle: Prentice Hall, 1996.

Grisby, J. E. Art and Ethnics. Dubuque: William. C. Brown Co., 1977.

Harris, H. W. Introduction: A conceptual overview of race, ethnicity, and identity. In H.W. Harris, H.C. Blue \& E. E. H. Griffith, (eds.), Racial and Ethnic Identity: Psychological Development and Creative Expression. New York: Routledge, 1995.

Hein, $H$. The role of feminist aesthetics in feminist theory. The Journal Of Aesthetics and Art Criticism (48): 281-289. 1990.

Hutchinson, J. \& A.D. Smith (eds.), Ethnicity. New York: Oxford University Press, 1996.

LaDuke, B. Women Artists - Multicultural Visions. Trenton: The Red Sea Press. 1992.

Lippard, L. Mixed Blessings - New Art in a Multicultural America. NY: Pantheon Books, 1990.

Lopez, Y. M. \& M. Roth. Social protest: Racism and sexism. In N. Broude, N. \& M.D. Garrard (eds.), The Power of Feminist Art. New York: Harry N. Abrams, 1994.

Lovelace, C. Weighing in on feminism. Art News (May) 140-145, 1997.

Machida, M. , (re)-ORIENTING. In J. Frueh, C.L. Langer, \& A. Raven (eds.), New Feminist Criticism. New York: Icon Editions, 1991.

Merriam-Webster Dictionary (Home \& Office Ed.), Springfield, MA: Merriam-Webster, 1998.

Moore, C. T. (1998) Socialist feminism frequently asked questions [On-line]. Available: http:www.ncf.carleton.ca/ip/sigs/life/feminism/faqs/socfem.faq

Ringer, B. B. \& E.R. Lawless, Race - Ethnicity and Society. New York: Routledge, 1989.

Royce, A. P. Ethnic Identity, Strategies of Diversity. Bloomington: Indiana University Press, 1982. 
Ryan, B. Feminism and The Women's Movement. New York: Routledge, 1992.

Seidman, I., Interviewing as Qualitative Research. New York: Teachers College Press, 1998.

Solomon, R. C. \& K. M. Higgins, A Short History of Philosophy. New York: Oxford University Press, 1996.

Stein, J., Collaboration, In N. Broude \& M.D. Garrard (eds.), The Power of Feminist Art. New York: Harry N. Abrams, 1994.

Touchette, C. Multicultural strategies for aesthetic revolution, In J.. Frueh, C. L. Langer, C. L. \& A. Raven (eds.), New Feminist Criticism: Art, Identity, Action. New York: Icon Editions, 1991.
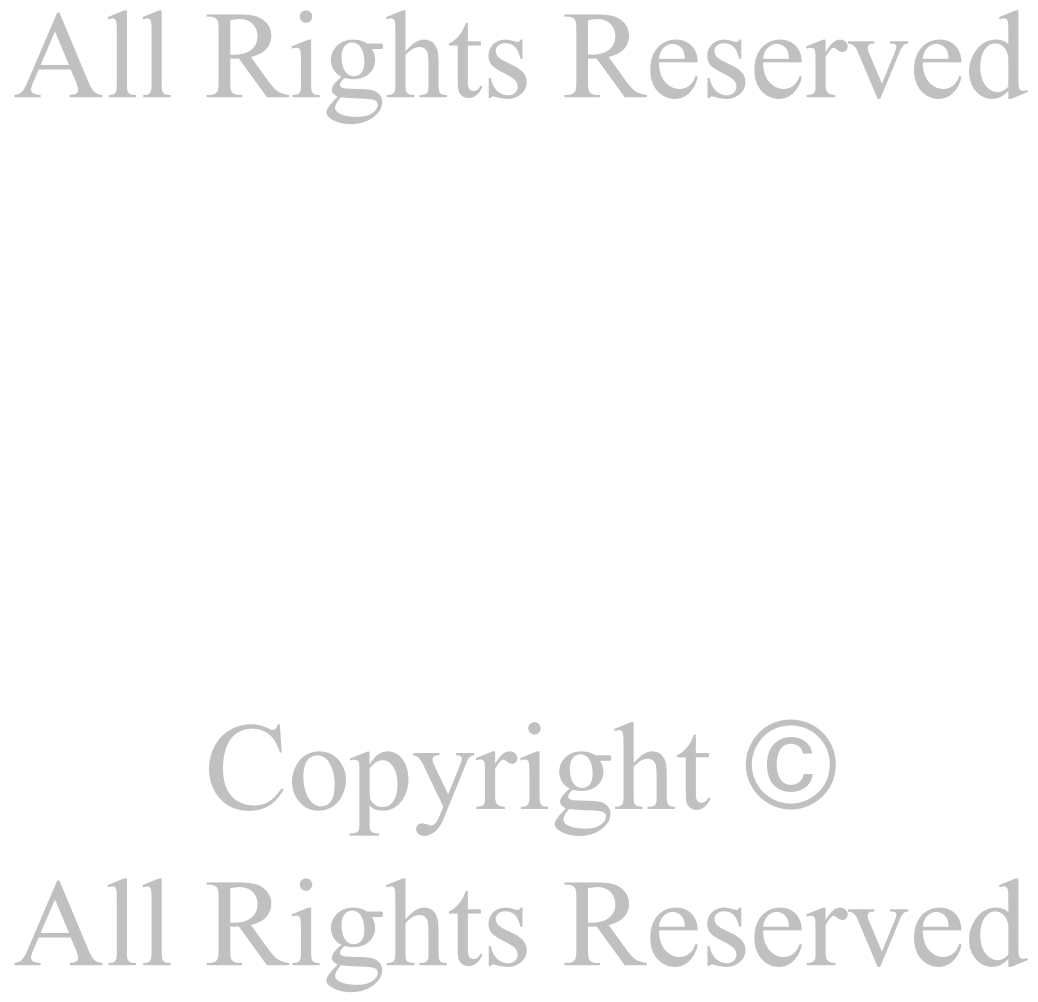